\section{The mental health of Korean immigrants in São Paulo, Brazil}

\author{
Saúde mental dos imigrantes coreanos em \\ São Paulo, Brasil
}

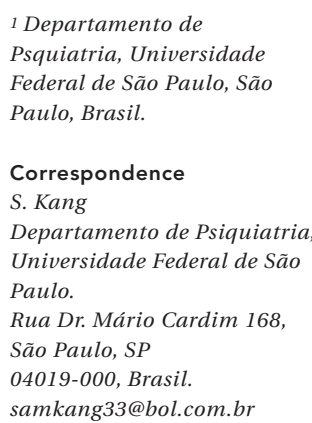

\begin{abstract}
This study investigated the frequency of lifetime mental disorders among Korean immigrants in the city of São Paulo, Brazil. Snowball sampling with multiple focuses was used to recruit Korean immigrants older than 18 years and living in São Paulo. A total of 324 Korean immigrants were selected and their mental status was evaluated using a structured interview, namely the Portuguese or the Korean version of the Composite International Diagnostic Interview 2.1. The diagnoses of mental disorders were made according to the ICD-10. The frequency of any lifetime psychiatric disorder was $41.9 \%$. The frequencies of main disorders were: anxiety disorder, 13\% (post-traumatic stress disorder, 9.6\%); mood disorder, 8.6\%; somatoform disorders, 7.4\%; dissociative disorder, 4.9\%; psychotic disorder, 4.3\%; eating disorder, $0.6 \%$; any substance (tobacco, alcohol, drugs) use disorder, 23.1\%. The frequency of any psychiatric disorder except alcohol and tobacco use disorders was $26.2 \%$. Korean immigrants have more psychiatric disorders than the Korean population in Korea, particularly post-traumatic stress disorder, and almost the same rate as the Brazilian population. Mental health authorities should promote a healthier integration and the development of culturally sensitive mental health programs for Korean immigrants.
\end{abstract}

Mental Disorders; Mental Health; Imigrants
Sam Kang 1

Denise Razzouk ${ }^{1}$

Jair Jesus de Mari 1

Itiro Shirakawa 1

\section{Introduction}

Population studies have shown that immigrants are more vulnerable to mental health disorders than the individuals in their countries of origin who have not emigrated. Among Mexican immigrants in the United States, $33.8 \%$ had some form of lifetime psychiatric disorder, whereas the prevalence rate among Mexicans in Mexico was 24.7\% 1. Italians in Paris had more depressive episodes $(17.6 \%$ vs. $13.6 \%)$ and dysthymia $(7.1 \%$ vs. $4 \%$ ) in their lifetime than the population in their country of origin 2 . The estimated rate of minor psychiatric disorders among Japanese-Brazilians in Japan was $17.8 \%$, and $3.2 \%$ among JapaneseBrazilians in Brazil 3.

Although population cross-sectional studies cannot show whether immigrants already had more mental problems before immigration than individuals who stayed in their country of origin, longitudinal studies may compare mental disorder rates before and after immigration. Jewish people that emigrated from the Soviet Union to Israel were followed up for five years, and results showed that they had more depressive and anxiety disorders after immigration: major depression - from $1.9 \%$ to $3.2 \%$; dysthymia - from $2 \%$ to $3.5 \%$; and anxiety disorders - from $3.9 \%$ to $5.2 \% 4$.

Studies with patients in psychiatric hospitals identified that different psychiatric disorders were associated with immigration. Studies con- 
ducted in American hospitals found a greater rate of immigrants among patients with bipolar disorder $(20.6 \%)^{5}$ and unipolar depressive disorders (19\%) ${ }^{6}$. A greater risk of schizophrenia was found among Afro-Caribbeans in England than among the local population (odds ratio $-\mathrm{OR}=$ 5-18) 7. Among Iranian immigrants in Canada, greater rates of psychiatric diagnoses were found for depression and anxiety disorders (60\%) and post-traumatic stress disorder $(10 \%) 8$.

When immigrants leave their country of origin and come into contact with a new reality, they are faced with several changes: environmental (place and type of residence, population characteristics); biological (food, local diseases); cultural (political, economic, religious, linguistic differences); and psychological (identity, values, internal references). These changes are experienced as stressors, which may increase vulnerability to mental disease 9,10 . However, each group of immigrants should be investigated with their particularities in mind, such as the country of origin, the country of residence, the time and reasons of immigration.

Brazil is a country that is largely made up of immigrants and their descendents. According to the latest Brazilian census (Instituto Brasileiro de Geografia e Estatística. Censo Demográfico de 2000. http://www.ibge.gov.br, accessed on $15 / \mathrm{May} / 2002)$, there are 685,000 immigrants in Brazil, $87 \%$ of whom come from 15 countries. Korean immigration to Brazil started in 1963 with the arrival of a small group of individuals $(n=92)$. The Korean immigrant community grew over the following decades with the arrival of groups organized by the Korean government and illegal immigrants that entered the country through the borders of neighboring countries, such as Paraguay, Bolivia and Argentina. Illegal Korean immigrants were granted amnesty by the Brazilian government at four different times (1969, 1981, 1989 and 1998). There are about 50,000 Koreans in Brazil, representing about $20 \%$ of the total number of immigrants that have been in Brazil for less than 10 years.

No surveys have been conducted about the mental health of Korean immigrants in Brazil. This population emigrated from a country with a lower prevalence of mental disorders (32.6\%) 11 than the country of resettlement (45.9\%) 12 . This is a particularly appropriate time to study the mental health of first-generation Korean immigrants in Brazil and this study investigated the frequency of psychiatric disorders among Korean immigrants in São Paulo and compared it with rates found in Korea.

\section{Method}

\section{Sample population}

São Paulo was selected because it has the largest Korean immigrant community in Brazil (98\%). The sample of Korean immigrants was recruited from the community according to the following inclusion criteria: to be a Korean immigrant older than 18 years and living in São Paulo. The minimum sample size $(n=257)$ was based on an estimate of the proportion of respondents who were likely to have experienced a lifetime mental disorder: 40\% (standard error - SE $=3 \%$ ) 13 .

As no list of Korean immigrants in Brazil was available, the subjects were recruited at immigrant community churches and commercial businesses. Participants and the group of interviewers were asked to introduce their friends into the survey.

\section{Instruments}

A standardized psychiatric interview, the Portuguese version of the Composite International Diagnostic Interview 2.1 (CIDI 2.1) 14 and the equivalent Korean version 15, was applied to the immigrants together with a questionnaire about immigration-related issues specifically designed for this study. The CIDI 2.1 is a structured interview schedule developed by the World Health Organization (WHO) and based on the National Institute of Mental Health Diagnostic Interview Schedule. It was designed to estimate the prevalence of mental disorders across countries or geographic regions. The interview can be used by trained lay interviewers. The questionnaire has questions on socio-demographics and migration-related issues: age at emigration; time in the country; language knowledge; self-rated acculturation level; self-rated socioeconomic status according to two references - immigrant community and general society; perception of prejudice for being an immigrant; participation in immigrant associations.

\section{Procedure}

Eleven bilingual interviewers, fluent in Portuguese and Korean, were recruited for this study. All of them were college students with various majors, and were trained at the CIDI Training Center in Brazil at the Universidade Federal de São Paulo.

As no list of Korean immigrants in Brazil was available, the participants were recruited at immigrant community churches. Two Protestant and one Catholic churches were selected from 44 
immigrant churches located in a city area with a high concentration of immigrants. At the first Protestant church visited, 100 subjects were selected from the list of 350 members and were contacted by telephone. This procedure proved to be complicated and to yield a very high refusal rate. Subsequently, the field coordinator and principal investigator held a meeting with leaders of small groups from the church, in order to explain the importance of the study and request that pamphlets be distributed to invite volunteers. This method proved to be more efficient and was used in all three religious institutions.

Participants were asked to introduce one nonreligious friend to be a control for sample bias associated with religiosity. This sampling project was based on the proportion of the population of Korea that is religious (50\%). They had great difficulty in indicating non-religious friend(s), and the authors decided to accept friends with a religious background.

In the face of high levels of religiosity among the first sample, respondents were also recruited at commercial businesses run by Korean immigrants in order to check immigrant religiosity. In the area of Korean concentration, four commercial streets were selected; from each street, one block was chosen and all commercial businesses were visited by a field coordinator. Each respondent was asked to indicate friends.

However, due to a low rate of indication by the first and second group of subjects, the interviewers were also asked to indicate their friends for the study. This method was used to interview undocumented immigrants 16 .

Before the application of the interview, written informed consent was obtained after providing respondents with a full description of the study. Interviews were conducted in Portuguese or Korean according to the respondent's preference. The average length of interview was 75 minutes. Data collection began in July 2004 and ended in June 2005.

\section{Statistical analysis}

The CIDI (ICD10_lt.sco) software (World Health Organization, Geneva, Switzerland), which generates psychiatric disorders according to International Classification of Diseases, 10th Revision (ICD-10) criteria, was used to establish diagnoses. The CIDI 2.1 provides lifetime, 12-month and 1 -month psychiatric diagnoses. In this survey, only lifetime disorders according to ICD-10 were reported. The 66 diagnoses provided by the program of CIDI 2.1 were grouped into diagnostic categories.

\section{Results}

There were different refusal rates in the 3 snowball focuses. At the religious institutions, about 3,700 immigrants were contacted through telephone and fliers and only 124 (3.4\%) accepted to be interviewed. They indicated 36 friends/ relatives and 11 (31\%) accepted to answer the questionnaires. The refusal rate was $80 \%$ when subjects were contacted by telephone and $96.6 \%$, when the contact was made through fliers. From the 58 commercial businesses visited by a field coordinator, 23 subjects (40\%) participated in the survey. They indicated 12 friends/relatives, and 11 (92\%) agreed to participate. The group of interviewers indicated 121 friends/relatives, and 116 (96\%) agreed to participate. These subjects further indicated 55 friends/relatives, and 39 (71\%) agreed to participate. Each snowball-sampling effort ended up in the second stage due to difficulties or refusals to indicate friends.

\section{Demographic characteristics}

The sample comprised 162 men and 162 women. The mean age was 35 years (standard deviation - SD $=13.1$ ) and $53.1 \%$ were married. Most participants (65.1\%) had emigrated when young, at an age of up to 20 years, and almost half (47.5\%) had been living in Brazil for up to 15 years. The most common occupations were self-employed professionals (55.7\%), students (23.6\%) and employees $(10.8 \%)$. Most had a high family income (88.3\%; > U\$ 12,000.00 per year) and high educational level (61.7\%; > 12 years of schooling) for the Brazilian context. Almost all participants (96.6\%) were religious.

\section{Frequency of psychiatric disorders}

The lifetime frequency of psychiatric disorders according to ICD-10 for the total sample is shown in Table 1 .

Nearly $42 \%$ of the sample had at least one lifetime mental disorder. The most prevalent disorder was substance (alcohol, tobacco, drug) use disorder (23.1\%). The second most frequent was anxiety disorder (13\%), followed by mood (8.6\%), somatoform (7.4\%), dissociative $(4.9 \%)$, psychotic $(4.3 \%)$ and eating $(0.6 \%)$ disorders. Of all subjects, $9.6 \%$ had post-traumatic stress disorder. Excluding alcohol and tobacco use disorder, $26.2 \%$ had at least one lifetime psychiatric disorder. Of all respondents, $18.2 \%$ had at least one lifetime anxiety disorder or mood disorder. The number of subjects that sought any kind of medical assistance in the previous year was investigated. Of all participants, $22.5 \%$ obtained 
Frequency of International Classification of Diseases, 10th Revision (ICD-10) psychiatric disorders.

\begin{tabular}{|c|c|c|c|c|}
\hline ICD-10 diagnosis & $n(N=324)$ & $\%$ & Korea * (\%) & Brazil ** $(\%)$ \\
\hline Any disorder & 135 & 41.7 & 32.6 & 45.9 \\
\hline Any disorder but tobacco dependence & 113 & 34.9 & 27.0 & 33.1 \\
\hline Any disorder but alcohol/tobacco use & 85 & 26.2 & 13.2 & - \\
\hline Substance use disorder & 75 & 23.1 & - & 27.3 \\
\hline Alcohol use disorder & 42 & 13.0 & 16.8 & - \\
\hline Alcohol abuse & 34 & 10.5 & 7.1 & - \\
\hline Alcohol dependence & 19 & 5.9 & 9.8 & 5.5 \\
\hline Tobacco use disorder & 51 & 15.7 & 11.1 & - \\
\hline Tobacco abuse & 22 & 6.8 & 2.9 & - \\
\hline Tobacco dependence & 29 & 9,0 & 10.2 & 25.0 \\
\hline Drug use disorder & 4 & 1.2 & 0.25 & - \\
\hline Drug abuse & 4 & 1.2 & 0.2 & - \\
\hline Drug dependence & 2 & 0.6 & 0.05 & 1.1 \\
\hline Any anxiety/mood disorders & 59 & 18.2 & - & 24.0 \\
\hline Any anxiety disorder & 42 & 13.0 & 9.1 & 12.5 \\
\hline Generalized Anxiety disorder & 15 & 4.6 & 2.3 & 4.2 \\
\hline Panic disorder & 1 & 0.3 & 0.4 & 1.6 \\
\hline Any phobia & 4 & 1.2 & & 8.4 \\
\hline Agoraphobia & 2 & 0.6 & 0.3 & 2.1 \\
\hline Specific phobia & 1 & 0.3 & 5.2 & 4.8 \\
\hline Social phobia & 1 & 0.3 & 0.2 & 3.5 \\
\hline Obsessive-compulsive disorder & - & - & 0.8 & 0.3 \\
\hline Post-traumatic stress disorder & 31 & 9.6 & 1.7 & - \\
\hline Any mood disorder & 28 & 8.6 & 4.7 & 18.4 \\
\hline Depressive episode & 20 & 6.2 & 4.1 & 16.8 \\
\hline Dysthymia & 8 & 2.5 & 0.5 & 4.3 \\
\hline Depressive disorder (depressive episode/dysthymia) & 27 & 8.3 & - & 18.1 \\
\hline Bipolar disorder & 1 & 0.3 & 0.2 & 1.0 \\
\hline Somatoform disorder & 24 & 7.4 & 0.6 & 6.0 \\
\hline Dissociative disorder & 16 & 4.9 & - & 2.2 \\
\hline Psychotic disorder & 14 & 4.3 & 1.2 & 1.9 \\
\hline Schizophrenia & 5 & 1.5 & 0.2 & - \\
\hline Eating disorder & 2 & 0.6 & 0.2 & - \\
\hline Bulimia nervosa & 2 & 0.6 & 0.03 & 1.5 \\
\hline Anorexia nervosa & 1 & 0.3 & 0.2 & - \\
\hline
\end{tabular}

* Data from Ministry of Health and Welfare of Korea 11 ( $N=6,275$; Diagnostic and Statistical Manual of Mental Disorders, 4th Edition - DSM-IV criteria);

** Data from Andrade et al. 12 ( $N=1,464 ;$ ICD-10 criteria).

general medical service; $3.4 \%$ sought emergency services; and $1.9 \%$ used the services of a mental health professional (psychiatrist, psychologist or social worker).

\section{Discussion}

This is the first study about the mental health of immigrants in Brazil using the CIDI 2.1. Results show that Korean immigrants in Brazil have a rate of lifetime mental disorders $(41.9 \%)$ that is between the prevalence of Korea (32.6\%) 11 and Brazil (45.9\%) ${ }^{12}$. The prevalence surveys in Korea and Brazil used the same diagnostic instrument as this study (CIDI 2.1), but different diagnostic criteria: Diagnostic and Statistical Manual of Mental Disorders, 4th Edition (DSM-IV) in Korea and ICD-10 in Brazil. A cautious comparison of results is recommended since ICD-10 criteria identify more cases of depression and fewer cases of anxiety disorders than the DSM-IV criteria 17. 
The population in this survey had higher rates in all categories of psychiatric diagnoses than Koreans in Korea. The rate of any lifetime disorder except alcohol and tobacco use disorder among immigrants was almost twice the rate for Koreans in their native country $(26.2 \%$ vs. $13.2 \%$ ). This result is in agreement with other studies that demonstrated that the pattern of mental health among immigrants was unfavorable when compared to the population in their country of origin: Mexicans in the United States 1, Italians in Paris 2 and Japanese-Brazilians in Japan compared with those in Brazil 5. The patterns of psychiatric disorders were not homogenous in the different diagnostic categories when compared to those in the Brazilian population: Korean immigrants have more psychotic ( $4.3 \%$ vs. $1.9 \%)$, dissociative $(4.9 \%$ vs. $2.2 \%$ ) and somatoform disorders (7.4\% vs. $6 \%)$, fewer mood disorders (8.6\% vs. $18.4 \%$ ) and substance use disorders ( $23.1 \%$ vs. $27.3 \%)$, and a similar rate of anxiety disorders ( $13 \%$ vs. $12.5 \%)$.

Studies of Afro-Caribbeans in Britain suggest that social and environmental adversities, such as unemployment, early separation from parents, inadequate housing, and experiences of racism, are risk factors for immigrants to develop a severe mental disorder 7. However, in the case of Korean immigrants in Brazil, social adversities may not be associated with the high rate of psychotic disorders, since $88.3 \%$ of the subjects have an annual income greater than U\$ $12,000.00$, which can be regarded as middle or high income in Brazil. A survey on 130 Japanese-Brazilian patients that went to Japan to work but had to come back to Brazil due to mental problems showed that $76.1 \%$ had a psychotic disorder. That study pointed out that experiencing a cultural change might be a stressful factor, which could explain the onset of the psychotic crises 18 . In the case of the participants in this survey, the experience of immigration might have increased their vulnerability, since immigration may precipitate the predominance of psychotic mechanisms by rupture of the balance between psychological conflicts and defenses 10 .

The western definition of psychiatric disorders, with its emphasis on biological factors, may increase the rate of somatoform disorders in communities with culturally different symptoms 19 , particularly among Asians 20 , who show more physical complaints than psychological symptoms 21,22. However, a higher frequency of somatoform disorders among immigrant Koreans than among non-immigrant Koreans $(7.4 \%$ vs. $0.6 \%$ ) raises questions about the role of immigration on the onset of this psychiatric disorder.
Substance use disorder was the most prevalent group of disorders in this study. The drug dependence rate was between the prevalence rate for Koreans in Korea and that for the Brazilian population. However, both tobacco (9\%) and alcohol dependence rates $(5.9 \%)$ were similar to the lower prevalence in the two populations: tobacco dependence, similar to that for Koreans in Korea (10.2\% vs. $25 \%$ for Brazilians); and alcohol dependence, similar to that for Brazilians (5.5\% vs. 9.8\% for Koreans in Korea). These results differ from those found in a survey of elderly Koreans in Los Angeles, which showed similar rates of alcohol use disorder for immigrants (19\%) and for the population of their native country $(21.7 \%) 20,23$. The results of our survey may have been affected by the religiosity of the subjects: most were Protestants $(68.5 \%)$, whose religion has rules against substance use.

The rate of mood disorders for immigrant Koreans $(8.6 \%)$ is double the rate for non-immigrant Koreans $(4.7 \%)$ and less than half of that among Brazilians (18.4\%). Comparing the findings of this study with those of other surveys, which used the same diagnostic instrument, our study subjects had a lower rate of mood disorders than Mexican-Americans (12.1\%) 1 and Sardinians in Paris (17.6\%; depressive episode) 2 . The comparison with Chinese-Americans revealed a similar rate of depressive episodes (6.2\% vs. $6.9 \%)$, but a lower rate of dysthymia (2.5\% vs. $5.2 \%) 24$. Surveys show that Asians have lower rates of mood disorders than Western people because they rarely report psychological complaints 21,22,24. However, even considering this culturally different psychopathological pattern among Asians, Korean immigrants have more depressive disorders (8.3\%, depressive episode/dysthymia) than other Asian communities in Brazil: Japanese-Brazilians (3.2\%; using the Self Reported Questionnaire - SRQ-20) 3 and Chinese-Brazilians (4.8\%; using the Beck Depression Inventory) 22. Although rates obtained by using different instruments are not easily compared, the higher rates of mood disorders among subjects from this study, compared with the population of their native country and other Asian communities in Brazil, may indicate a higher vulnerability to mood disorders among this community.

A higher rate of anxiety disorders among Korean immigrants than among Koreans in Korea ( $13 \%$ vs. $9.1 \%$ ) may be explained by the strikingly higher rate of post-traumatic stress disorder among immigrants in this study (9.6\% vs. $1.7 \%$ ). The analysis of the CIDI 2.1 section that corresponds to PTSD (section $\mathrm{K}$ ) revealed that $35 \%$ of subjects had suffered a physical attack or assault; $23 \%$ were involved in accidents that were life risk- 
ing; $20 \%$ had seen somebody being severely injured or killed; and $16 \%$ had been threatened with fire arms, kidnapped or secluded. Some studies report that immigrants are vulnerable to develop post-traumatic stress disorder due to their feelings of helplessness 10,25. Severe urban violence in São Paulo in addition to the stressful and traumatic experiences associated with migration may promote the onset of post-traumatic stress disorder in immigrants. Comparative studies about urban violence and post-traumatic stress disorder in both immigrant and non-immigrant populations should investigate whether immigrants are suffering more violence and whether violent experiences lead to more post-traumatic stress disorder among immigrants than among the general population.

The percentage of study participants that sought mental health services $(1.9 \%$ in the previous year) was lower than that found for Brazilians $(7.7 \%$ in the previous month) 12 and than the potential estimate of $25 \%$ calculated according to the frequency of mental health problems found in this study 26 . The explanation for such a low percentage may be cultural because mental problems are seen as "mental weakness" or a "reason to be ashamed". This may also be due to difficulties in communication, because there are no public services available for culturally diverse populations. Strategies should be developed to bring adequate treatment to this population.

This survey shows higher participation when the participants are contacted personally. The lowest refusal rate (4\%) is found among those indicated by the interviewers and the highest refus- al rate $(96.6 \%)$, among those contacted at community churches through fliers. It indicates the importance of a sampling method that is based on personal contact to promote higher participation among Asian immigrants.

Some of the limitations of this survey are the high refusal rate, low rate of participation of non-religious population and difficulties/refusals to indicate friends, which limited the snowball design. It may limit the generalization of results to the whole community of Korean immigrants in Brazil. Although this study worked with the best available number at the time of the survey, further studies are required to control possible sample bias and to find a more accurate rate of mental disorders for the immigrant community.

Our results show that the prevalence of psychiatric disorders for Korean immigrants is greater than for Koreans in Korea and almost the same as for the Brazilian population. Furthermore, considering the high religiosity of the subjects and protecting function of religion, the rate of mental disorders among the immigrants might be higher than that found in this study. The results of this survey, which revealed a more unfavorable pattern of mental health among immigrants than among the population in their native country, cannot be generalized to all immigrants in Brazil or to all Korean immigrants in other countries. However, attention from mental health authorities is required for a healthier integration of new Korean immigrants, and the development of culturally sensitive mental health services for this population. 


\section{Resumo}

Este estudo verificou a freqüência de transtornos psiquiátricos em uma comunidade de imigrantes coreanos na cidade de São Paulo, Brasil. A amostragem snowball com vários focos foi utilizada para contatar os imigrantes coreanos, acima de 18 anos e residentes em São Paulo. Foram selecionados 324 sujeitos, cuja saúde mental foi avaliada por meio de uma entrevista estruturada, Composite International Diagnostic Interview 2.1, nas versões em português e coreano. Foi utilizado o critério de diagnóstico CID-10. A freqüência de algum diagnóstico psiquiátrico na vida foi de 41,9\%. As freqüências de principais diagnósticos na vida foram: transtornos de ansiedade, 13\% (transtorno de estresse pós-traumático, 9,6\%); transtornos do humor, 8,6\%; transtornos somatoformes, 7,4\%; transtornos dissociativos, 4,9\%; transtornos psicóticos, 4,3\%; transtornos alimentares, 0,6\%; transtornos decorrentes de substâncias (álcool, tabaco ou drogas), 23,1\%. A freqüência de diagnósticos psiquiátricos na vida, excluindo-se os decorrentes de álcool e tabaco, foi de 26,2\%. Os imigrantes coreanos apresentam mais transtornos psiquiátricos do que a população coreana na Coréia, especialmente transtorno de estresse pós-traumático, $e$ uma taxa semelhante à encontrada na população brasileira. As autoridades de saúde mental devem promover uma integração mais saudável por meio de programas culturalmente sensiveis aos imigrantes coreanos.

Transtornos Mentais; Saúde Mental; Imigrantes

\section{References}

1. Alderete E, Vega WA, Kolody B, Gaxiola SA. Effects of time in the United States and Indian ethnicity on DSM-III-R psychiatric disorders among Mexican Americans in California. J Nerv Ment Dis 2000; 188:90-100.

2. Carta MG, Kovess V, Hardoy MC, Morosini P, Murgia S, Carpiniello B. Psychiatric disorders in Sardinian immigrants to Paris: a comparison with Parisians and Sardinians resident in Sardinia. Soc Psychiatry Psychiatr Epidemiol 2002; 37:112-7.

3. Miyasaka LS, Otsuka K, Tsuji K, Atallah AN, Kunihiro J, Nakamura Y, et al. Mental health of two communities of Japanese-Brazilians: a comparative study in Japan and in Brazil. Psychiatry Clin Neurosci 2002; 56:55-64.

4. Zilber N, Lerner Y, Eidelman R, Kertes J. Depression and anxiety disorders among Jews from the former Soviet Union five years after their immigration to Israel. Int J Geriatr Psychiatry 2001; 16:993-9.

\section{Contributors}

S. Kang participated in the study design, data collection and analysis and writing of the article. D. Razzouk and I. Shirakawa collaborated with the study design, data analysis, revision and approval of the final version of the article. J. J. Mari contributed to the study design, revision and approval of the final draft.

\section{Acknowledgments}

We would like to thank Dr. Myung Je Cho and Bong Jin Hahm for permission to use the Korean version of the Composite International Diagnostic Interview 2.1 (KCIDI 2.1). The fieldwork for this study was funded by a grant from the São Paulo Research Foundation (FAPESP, grant number 03/06628-0).
5. Pope HG, Kullgren G, Caldera T. Migrations and manic-depressive illness. Compr Psychiatry 1983; 24:158-65.

6. Grove W, Clayton PJ, Endicott J, Hirschfeld RMA, Andreasen NC, Klerman GL. Immigration and major affective disorder. Acta Psychiatr Scand 1986; 74:548-52.

7. Wessely S, Castle D, Der G, Murray RM. Schizophrenia and Afro-Caribbeans. A case-control study. Br J Psychiatry 1991; 159:795-801.

8. Bagheri A. Psychiatric problems among Iranian immigrants in Canada. Can J Psychiatry 1992; 37:7-11.

9. Berry JW, Kim U, Mine T, Mod D. Comparative studies of acculturative stress. Int Migr Rev 1987; 21:491-511.

10. Grinberg LA, Grinberg R. Psicoanálisis de la migración y del exilio. Madrid: Alianza; 1984. 
11. Ministry of Health and Welfare of Korea. Prevalence of DSM-IV psychiatric disorders in Korea. http:// www.mohw.go.kr (accessed on 20/Mar/2003)

12. Andrade L, Walter EE, Gentil V, Laurenti R. Prevalence of ICD-10 mental disorders in a catchment area in the city of São Paulo, Brazil. Soc Psychiatry Psychiatr Epidemiol 2002; 37:316-25.

13. Rosner B. Fundamentals of biostatistics. Belmont: Wadsworth; 1995.

14. Quintana MIS. Validity of Composite International Diagnostic Interview (CIDI/WHO) version 2.1 in mental health services in Brazil [Doctoral Dissertation]. São Paulo: Universidade Federal de São Paulo; 2005.

15. Cho MJ, Hahm BJ, Suh DW, Hong JP, Bae JN, Kim JK, et al. Development of a Korean version of the Composite International Diagnostic Interview (KCIDI). Journal of Korean Neuropsychiatry Association 2002; 41:123-37.

16. Cornelius MA. Interviewing undocumented immigrants. Int Migr Rev 1982; 16:378-411.

17. Wacker HR, Müllejans R, Klein KH, Battegay R. Identification of crises of anxiety disorders and affective disorders in the community according to ICD-10 and DSM-III-R by using the Composite International Diagnostic Interview (CIDI). Int J Methods Psychiatr Res 1992; 2:91-100.

18. Shirakawa I, Nakagawa D, Miyasaka LS. Emigração e transtornos mentais de brasileiros no Japão. J Bras Psiquiatr 2003; 52:75-80.
19. Villaseñor Y, Waitzkin H. Limitations of a structured psychiatric diagnostic instrument in assessing somatization among Latino patients in primary care. Med Care 1999; 37:637-46.

20. Lee CK, Kwak YS, Yamamoto J, Rhee H, Kim YS, Han JH, et al. Psychiatric epidemiology in Korea. Part I: Gender and age differences in Seoul. J Nerv Ment Dis 1990; 178:242-52.

21. Hsu LKG, Folstein MF. Somatoform disorders in Caucasian and Chinese Americans. J Nerv Ment Dis 1997; 185:382-7.

22. Wang YP, Andrade LH, Gorenstein C. Validation of the Back Depression Inventory for a Portuguesespeaking Chinese community in Brazil. Braz J Med Biol Res 2005; 38:399-408.

23. Yamamoto J, Rhee S, Chang DS. Psychiatric disorders among elderly Koreans in the Unites States. Community Ment Health J 1994; 30:17-27.

24. Takeuchi DT, Chung RC, Lin KM, Shen H, Kurasaki K, Chun CA, et al. Lifetime and twelve-month prevalence rates of major depressive episodes and dysthymia among Chinese-Americans in Los Angeles. Am J Psychiatry 1998; 155:1407-14.

25. Bhugra D. Migration and mental health: review article. Acta Psychiatr Scand 2004; 109:243-58.

26. Almeida-Filho N, Mari JJ, Coutinho E, França JF, Fernandes J, Andreoli SB, et al. Brazilian multicentric study of psychiatric morbidity. Methodological features and prevalence estimates. Br J Psychiatry 1997; 171:524-9.

Submitted on $02 /$ Jan/2008

Final version resubmitted on $04 / \mathrm{Jun} / 2008$ Approved on 01/Jul/2008 